\title{
Periodicity in structure, bonding, and reactivity for p-block complexes of a geometry-constraining triamide ligand
}

\author{
Katherine M. Marczenko, Joseph A. Zurakowski ${ }^{\dagger}$, Marcus B. Kindervater ${ }^{\dagger}$, Samantha Jee,
} Toren Hynes, Nicholas Roberts ${ }^{\ddagger}$, Seoyeon Park ${ }^{\ddagger}$, Ulrike Werner-Zwanziger, Michael Lumsden, David N. Langelaan, Saurabh S. Chitnis*

Dalhousie University, Department of Chemistry, 6274 Coburg Road, Halifax, Nova Scotia, Canada

\begin{abstract}
The use of pincer ligands to access non-VSEPR geometries at main-group centers is an emerging strategy for eliciting new stoichiometric and catalytic reactivity. As part of this effort, several different tridentate trianionic substituents have to date been employed at a range of different central elements, providing a patchwork dataset that precludes rigorous structure-function correlation. Here we report an analysis of periodic trends in structure (solid, solution, and gas phase), bonding, and reactivity based on systematic variation of the central element $(\mathrm{P}, \mathrm{As}, \mathrm{Sb}$, or $\mathrm{Bi}$ ) with retention of a single tridentate triamide substituent. In this homologous series, the central element can adopt either a bent or planar geometry. The tendency to adopt planar geometries increases descending the group with the phosphorus triamide (1) and its arsenic congener (2) exhibiting bent conformations, and the antimony (3) and bismuth (4) analogues exhibiting a predominantly planar structure in solution. This trend has been rationalized using the energy decomposition analysis. A rare phase-dependent dynamic covalent dimerization was observed for 3 and the associated thermodynamic parameters were established quantitatively. Planar geometries were found to engender lower LUMO energies and smaller band gaps as compared to bent ones, resulting in different reactivity patterns. These results provide a benchmark dataset to guide further research in this rapidly emerging area.
\end{abstract}

${ }^{\dagger}$ and ${ }^{\ddagger}$ denote equal contribution 


\subsection{Introduction}

The relationship between electronic structure and molecular geometry for main group molecules is generally well-explained in terms of Pauli repulsion between valence electron pairs (VSEPR model), ${ }^{1}$ with canonical geometries - trigonal planar, tetrahedral, pyramidal, trigonal bipyramidal, bent, etc. - being predicted and usually observed for the Group 13-16 elements. Insofar as VSEPR model geometries represent ground states that minimize electronic energies for the respective molecules, enforcing deviations from them is expected to engender novel electronic structures and reactivity.

Chart 1. Select examples of main group elements within geometry-confining tridentate pincer ligands.

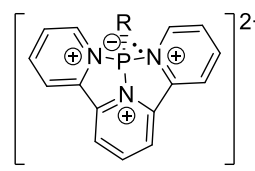

A

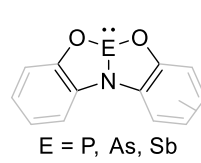

B

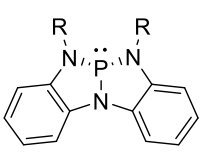

C

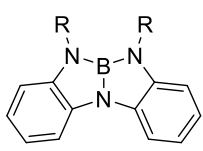

$\mathbf{F}$

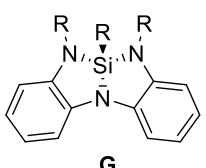

G
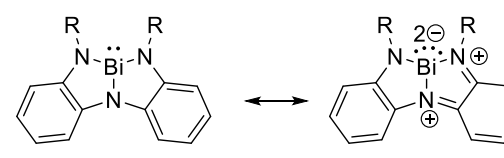

H (planar)

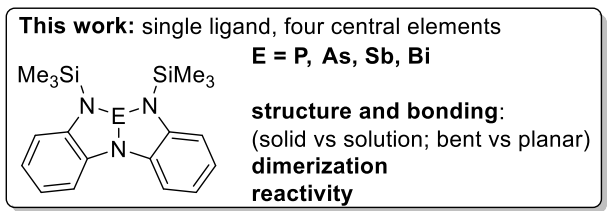

A major goal of electronic structure tuning in main group chemistry is the quest for the type of bond activation and catalysis that ennobles transition metals. Several recent examples show that planarityimposing tridentate ligands are a privileged class of substituents for achieving this goal as they distort classical VSEPR structures and offer chelate-enhanced stability. Stephan exploited a strained hemilabile ligand at phosphorus(III) cations for imparting air-stability to $\mathrm{C}-\mathrm{F}$ bond reduction catalysts $(\mathbf{A}) \cdot{ }^{2-4}$ Arduengo used tethered trianionic substituents to enforce planar bicyclic geometries at phosphorus, arsenic, and antimony compounds (B), resulting in ambiphilic reactivity. ${ }^{5-7}$ Radosevich has done pioneering work in evolving new geometry-constrained main group compounds including systems featuring constrained $\mathrm{P}$ (III) triamides that exhibit catalytic activity (C). ${ }^{8-13}$ The groups of Dobrovetsky, Goicoechea, Kinjo, and Aldridge have also achieved challenging stoichiometric bond activation chemistry by confinement of $\mathrm{P}$ (III) centres within tridentate $\mathrm{O}-\mathrm{N}-\mathrm{O}$ substituents $(\mathrm{B}, \mathbf{E}){ }^{14-16}$ Moving beyond phosphorus, tethered triamide ligands have been used by Dutton and Martin to achieve an approximately T-shaped planar geometry at boron $(\mathbf{F})^{17}$ and by Greb to achieve severely distorted tetrahedral arrangements at silicon that demonstrate novel dimerization modes $(\mathbf{G}) .{ }^{18-19}$ Recently, we showed that a bismuth complex of a triamide pincer 
exhibits a remarkable planar ground state for this element $(\mathbf{H}$, c.f. the bent phosphorus analogue $\mathbf{C})$ and lies on the cusp between $\mathrm{Bi}(\mathrm{I})$ and $\mathrm{Bi}(\mathrm{III})$ oxidation states, demonstrating reactivity patterns indicative of both extrema. ${ }^{20}$ Applications of tridentate-ligand bound planar $\mathrm{Bi}(\mathrm{I})$ compounds in catalysis have now started to appear in work by Cornella, ${ }^{21}$ following the comprehensive investigations by Breunig, Raţ and Dostàl of monoanionic pnictogen N-C-N chelates. ${ }^{22-26}$ Thus, orbital engineering by ligands that enforce unusual geometries is a powerful strategy for eliciting nonclassical reactivity with emerging applications in main group catalysis.

Currently several different classes of ligands have been employed at several different element centres providing a patchwork dataset that precludes a rigorous structure/function analysis. Moreover, most of the efforts have focused on the lighter elements $(B, S i, P)$. Given the rapidly evolving state of this field, we envisioned that a systematic longitudinal study examining how a geometry-constraining ligand modulates the structure, electronics, and reactivity at the central element within a periodic group would be timely and instructive. A related analysis by Dostàl and Cain had a significantly narrower focus, studying aromaticity and structural trends for monoanionic N-C-N ligands that are moreover restricted to planar geometries. ${ }^{27}$ In contrast, here we report a combined experimental and theoretical investigation into structure and reactivity of the phosphorus, arsenic, antimony, and bismuth complex of a single tethered trianionic N-N-N substituent that samples a larger parameter space in geometric and electronic structure due to the ligand's ability to support either bent or planar conformations and resonate between a triamido form an amido bis-imino form ${ }^{28}$ (see $\mathbf{H}$ in Chart 1). We evidence a remarkably dynamic structural chemistry, which has been studied in the solid, solution, and gas phase (the latter via DFT calculations). Periodic trends in the observed structural variations have been rationalized using state-of-the-art energy decomposition analyses and correlated with consequences for reactivity. The results provide a reference for predicting the outcome of geometric deformation across four principal quantum numbers in the p-block and reveal design principles for future research in this important area of main group chemistry.

\subsection{Results and Discussion}

\subsection{Syntheses}

The synthesis and characterization data for compounds 1 and 4 and the structure of the latter was communicated by us earlier. ${ }^{20}$ Lithiation of the triamide ligand $\mathbf{N}_{3} \mathbf{H}_{3}$, followed by reaction with one molar equivalent of $\mathrm{AsCl}_{3}$ gave compound 2 which was isolated as a crystalline solid in $55 \%$ yield. Quenching the lithiated ligand with $\mathrm{SbCl}_{3}$ to prepare compound 3 led to intractable mixtures from which no pure material could be isolated. Compound 3 was, however, accessible by amine elimination from $\mathrm{Sb}\left(\mathrm{NMe}_{2}\right)_{3}$. The reaction was found to be nearly quantitative by ${ }^{1} \mathrm{H}$ NMR spectroscopy and the product was isolated in $72 \%$ yield. As described later, this compound is dimeric in the solid state ( $\boldsymbol{3}_{\text {dim }}$ ) and monomeric in solution. Ligand coordination is a common strategy to stabilize monomeric analogues of otherwise 
multimeric heavy main group element compounds and we envisioned this approach may enable trapping of monomeric 3 in the condensed phase. Indeed, repeating the aminolysis between saturated solutions of $\mathrm{N}_{3} \mathrm{H}_{3}$ and $\mathrm{Sb}\left(\mathrm{NMe}_{2}\right)_{3}$ in a sealed flask and cooling the resulting reaction mixture without concentration yielded the monomeric bis-dimethylamine adduct $\mathbf{3}(\mathrm{dma})_{2}$. However, this species is exceptionally fragile and undergoes uncontrolled loss of the volatile amines under a stream of nitrogen or under vacuum to give the corresponding dimer, $\boldsymbol{3}_{\mathrm{dim}}$. Consequently, no reproducible spectroscopic analysis could be performed on samples of $\mathbf{3}(\mathbf{d m a})_{2}$, although, with rigorous cryogenic handling, single crystals suitable for diffraction were obtained to unambiguously establish its molecular structure. Although a precise mass yield for $3(\mathrm{dma})_{2}$ cannot be stated, formation of this adduct is understood to be quantitative because upon exposure to dynamic vacuum, it shows quantitative formation of $\mathbf{3}_{\text {dim }}$ with respect to the $\mathrm{Sb}\left(\mathrm{NMe}_{2}\right)_{3}$ starting material.

Compounds $1-4$, and $\mathbf{3}(\mathrm{dma})_{2}$ are air-sensitive but stable under an atmosphere of dry and deoxygenated nitrogen as solids and in hydrocarbon solutions. However, all compounds except 1 degrade over a span of 3-4 days upon dissolution in $\mathrm{CH}_{2} \mathrm{Cl}_{2}$ or $\mathrm{CDCl}_{3}$. The attempted syntheses of 1 and 2 from $\mathbf{N}_{3} \mathrm{H}_{3}$ and $\mathrm{P}\left(\mathrm{NMe}_{2}\right)_{3}$ or $\mathrm{As}\left(\mathrm{NMe}_{2}\right)_{3}$ were unsuccessful, likely due to the lower polarity of the $\mathrm{P}-\mathrm{N}$ and As-N bonds compared to the $\mathrm{Sb}-\mathrm{N}$ and $\mathrm{Bi}-\mathrm{N}$ bonds.

Scheme 1. Synthesis of compounds 1-4 and 3(dma) ${ }_{2}$.

a)

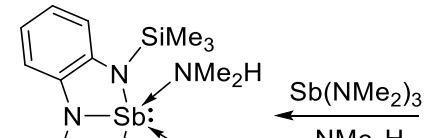

i) $3^{n} \mathrm{BuLi}$

ii) $\mathrm{ECl}_{3}$

$-3 \mathrm{LiCl}$
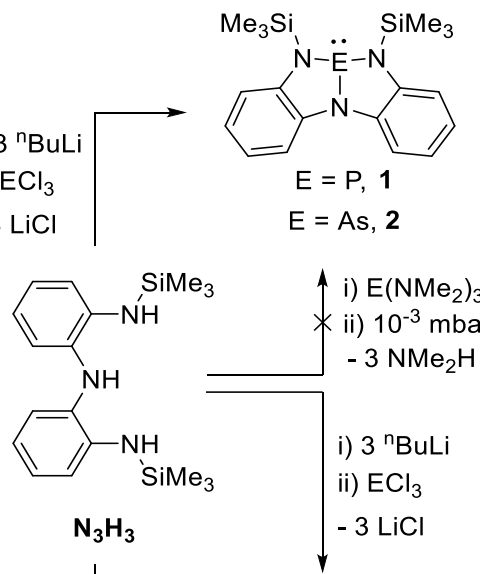

$3(\mathrm{dma})_{2}$

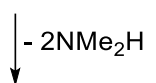

3

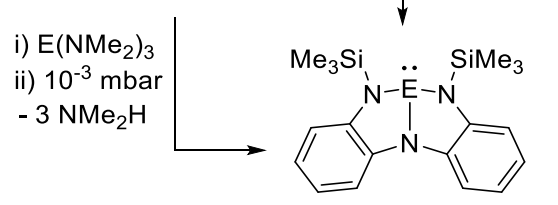

$\mathrm{E}=\mathrm{Sb}, 3$

$\mathrm{E}=\mathrm{Bi}, 4$

b)

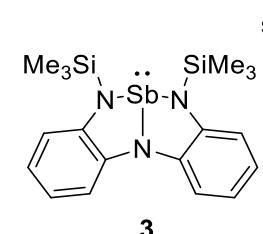

solution solid

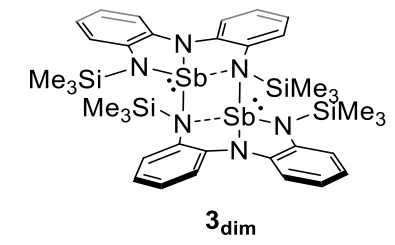

\subsection{Solid-Phase Structures}


The structures of triamides 1-4 in the solid-phase were investigated by a combination of single crystal X-ray diffraction (see Table 1) and solid-state Cross-Polarization/Magic Angle Spinning (CP/MAS) NMR spectroscopy.

While crystals of 1 were repeatedly found to be unsuitable for diffraction, a close analogue bearing $\mathrm{N}-$ $\mathrm{CH}_{3}$ groups instead of $\mathrm{N}-\mathrm{Si}\left(\mathrm{CH}_{3}\right)_{3}$ groups at the nitrogen was previously structurally characterized and found to be bent in the solid state. ${ }^{9}$ The ${ }^{31} \mathrm{P}$ NMR spectrum of 1 in toluene reveals a resonance at $\delta\left({ }^{31} \mathrm{P}\right)$ $=155.0 \mathrm{ppm}$, which is within $5 \mathrm{ppm}$ of the value reported for the $\mathrm{N}-\mathrm{CH}_{3}$ derivative (159 ppm). We have further studied 1 by solid-state ${ }^{31} \mathrm{P}$ NMR, which showed a resonance at $\delta\left({ }^{31} \mathrm{P}\right)=154.6 \mathrm{ppm}$, confirming that the dominant structure observed in solution is retained in the solid-phase (Figure S1). We therefore infer that $\mathbf{1}$ is isostructural to its $\mathrm{N}-\mathrm{CH}_{3}$ analogue and therefore also bent and monomeric in the solid state, and this view is supported by UV-Vis spectroscopy and DFT calculations (vide infra).

Figure 1. Views of the solid-state molecular structure of $\mathbf{2}$ (a), $\mathbf{3}_{\mathrm{dim}}(\mathrm{b}), \mathbf{3}(\mathbf{d m a})_{2}$ (c), and $\mathbf{4}$ (d). Nonessential hydrogen atoms have been omitted and the $\mathrm{CH}_{3}$ portions of the $\mathrm{Si}\left(\mathrm{CH}_{3}\right)_{3}$ groups have been truncated for clarity. Thermal ellipsoids are drawn at the $50 \%$ probability level. Key bond lengths and angles are given in Table 1.

a)

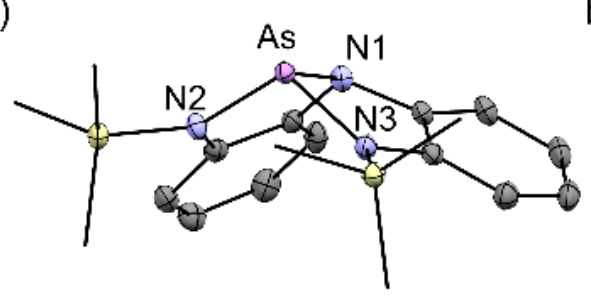

c)

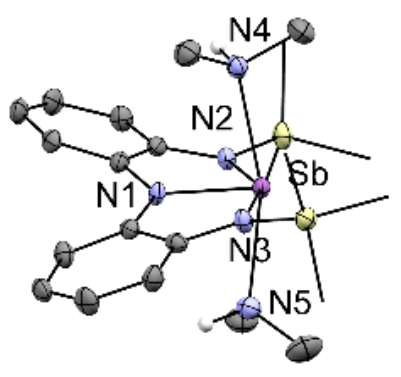

b)

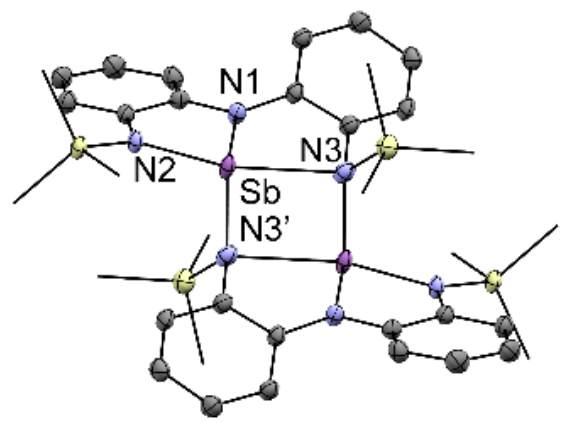

d)

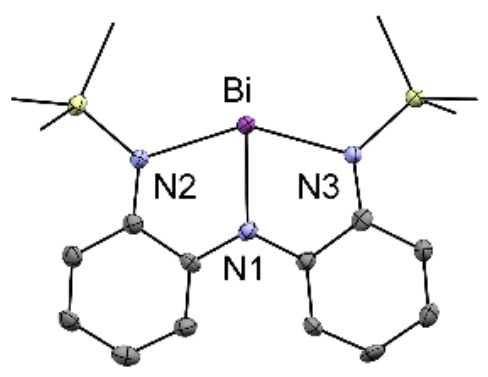

Compound 2 exhibits a distorted pyramidal geometry with $\mathrm{N}-\mathrm{As}-\mathrm{N}$ angles of $112.97^{\circ}, 87.76^{\circ}$, and $88.53^{\circ}$ (Figure 1a) The As-N3 bond [1.919(1) $\AA$ ] is marginally elongated compared to the As-N1 [1.877(1) $\AA]$ and the As-N2 [1.860(1) $\AA$ ] bonds. Consistent with the asymmetric As-N2 and As-N3 bond lengths, the two five-membered $\mathrm{C}_{2} \mathrm{~N}_{2}$ As rings in the structure show differing extents of planarity. In the ring comprised of N1-As-N2-C1-C2 atoms, the As atom is displaced $0.07 \AA$ above the plane defined by the N1$\mathrm{N} 2-\mathrm{C} 1-\mathrm{C} 2$ atoms. By comparison, the heavy element is approximately $0.35 \AA$ out of plane in the ring involving the N1-As-N3-C3-C4 atoms. The average of four $\mathrm{C}-\mathrm{N}$ bond lengths in 2 is 1.419(1) $\AA$, as 
expected for $\mathrm{C}-\mathrm{N}$ single bonds. The ${ }^{13} \mathrm{C}$ CP/MAS spectrum of 2 showed the expected 12 peaks for the distinct aromatic carbon atoms, with the carbon atoms connected to nitrogen resonating in the 138-150 ppm range and the remainder in the 110-125 ppm range (Figure S2).

Table 1. Selected bond lengths $(\AA)$ found in the solid phase for $2,3_{\operatorname{dim}}, 3(\mathrm{dma})_{2}$, and 4.

\begin{tabular}{|c|c|c|c|c|c|}
\hline \multirow[b]{2}{*}{ E-N } & \multirow{2}{*}{$\begin{array}{l}2 \\
1.860(1)\end{array}$} & \multirow{2}{*}{$\begin{array}{l}3_{\text {(dma)2 }} \\
2.069(2)\end{array}$} & \multicolumn{2}{|c|}{$3_{\mathrm{dim}}$} & \multirow{2}{*}{$\begin{array}{l}4 \\
2.303(4)\end{array}$} \\
\hline & & & $2.053(5)$ & $2.051(5)$ & \\
\hline & $1.877(1)$ & $2.195(3)$ & $2.075(4)$ & $2.076(4)$ & $2.282(3)$ \\
\hline & $1.919(1)$ & $2.200(2)$ & $2.136(5)$ & $2.141(7)$ & $2.181(4)$ \\
\hline \multirow[t]{4}{*}{$\mathbf{C}-\mathbf{N}$} & $1.407(2)$ & $1.392(4)$ & $1.402(6)$ & $1.398(6)$ & $1.363(7)$ \\
\hline & $1.409(2)$ & $1.393(4)$ & $1.403(6)$ & $1.403(6)$ & $1.383(6)$ \\
\hline & $1.430(2)$ & $1.398(3)$ & $1.417(7)$ & $1.410(7)$ & $1.388(6)$ \\
\hline & $1.439(2)$ & $1.409(4)$ & $1.445(6)$ & $1.447(8)$ & $1.362(7)$ \\
\hline \multirow[t]{2}{*}{ C-C } & $1.407(2)$ & $1.430(4)$ & $1.420(7)$ & $1.412(8)$ & $1.428(6)$ \\
\hline & $1.409(2)$ & $1.420(4)$ & $1.405(7)$ & $1.422(7)$ & $1.426(7)$ \\
\hline \multirow[t]{2}{*}{$\mathbf{N}-\mathbf{S i}$} & $1.764(1)$ & $1.738(2)$ & $1.821(6)$ & $1.753(5)$ & $1.740(4)$ \\
\hline & $1.751(1)$ & $1.737(2)$ & $1.746(4)$ & $1.830(7)$ & $1.747(4)$ \\
\hline \multirow[t]{2}{*}{$\mathrm{Sb}-\mathbf{N}$} & & $2.456(3)$ & $2.633(4)$ & $2.647(5)$ & \\
\hline & & 2.47 & & & \\
\hline
\end{tabular}

X-ray structural analysis of compound 3 revealed a dimeric structure with two tetracoordinate antimony centres within a centrosymmetric molecule (Figure 1b). Two modified monomeric units are horizontally displaced with respect to each other, forming $\mathrm{Sb}_{2} \mathrm{~N}_{2}$ rings as the central motif [N-Sb-N angle $80.55^{\circ}$ ]. The coordination geometry around $\mathrm{Sb}$ can be described as distorted seesaw with the outer $\mathrm{N}-\mathrm{Sb}$ bonds occupying the axial positions. The inversion center lies in the center of the planar $\mathrm{Sb}_{2} \mathrm{~N}_{2}$ ring. The shortest Sb-N bonds involve the Sb-N1 [2.053(5) Å], Sb-N2 [2.075(4) Å], and Sb-N3' [2.136(5) Å] atoms while the Sb-N3 distance [2.633(4) $\AA$ ] is significantly elongated. Thus 3 is interpreted as an extended dinuclear compound, featuring bent $\mathrm{Sb}$ centres engaged in two intramolecular dative interactions rather than a donor-acceptor dimer assembled by dative interaction between two planar $\mathrm{SbN}_{3}$ cores. Such dimerization has also been observed by Greb with silicon analogues of constrained triamides, although in the silane case, the central rather than external nitrogen atoms acts as the bridging site. ${ }^{18}$ The average $\mathrm{C}-\mathrm{N}$ bond lengths in $3_{\text {dim }}$ are 1.415(5) $\AA$ and thus comparable to the $\mathrm{C}-\mathrm{N}$ single bonds in 2 . The ${ }^{13} \mathrm{C}$ CP/MAS spectrum of solid $\mathbf{3}$ is consistent with its low symmetry and showed a complex superposition of lines arising 
from 12 independent aromatic carbon atoms per dinuclear molecule and the presence of two independent molecules in the unit cell (Figure S3).

Compound $\mathbf{3}(\mathbf{d m a})_{2}$ (Figure 1c) represents a ligand-stabilized version of monomeric $\mathbf{3}$ and its formation is understood in terms of the metal-centered LUMO of $\boldsymbol{3}_{\mathrm{dim}}$ (Figure S5) being antibonding with respect to the Sb-N3' bond and the LUMO of the hypothetical monomer 3 being a p-type orbital at a planar antimony centre (Figure S12). Consequently, the $\mathrm{N}_{3} \mathrm{Sb}$ core involving the tridentate ligand in $\mathbf{3}(\mathbf{d m a})_{2}$ is also planar $\left[179.10(1)^{\circ}\right]$, providing the first example of planar Lewis acidity at neutral Sb ${ }^{\text {III }}$ centres, which generally coordinate Lewis bases via Sb-X $\sigma^{*}$ antibonding orbitals around a pyramidal $\mathrm{SbX}_{3}$ molecule. $^{29-32} \mathrm{The} \mathrm{Sb}-$

$\mathrm{N} 1$ bond lengths in $\mathbf{3}(\mathbf{d m a})_{2}$ [2.069(2) $\AA$ ] is essentially unchanged from its value in $\mathbf{3}_{\text {dim }}$ while the Sb-N2/3 lengths are comparable to the Sb-N2 length in $\mathbf{3}_{\text {dim }}$, and nearly $0.5 \AA$ shorter than the value for Sb-N3 in the dimer.

We communicated the structure and bonding scheme of 4 previously ${ }^{20}$ but the key features are summarized here. Unique amongst the examined triamides, the $\mathrm{Bi}-\mathrm{N} 3$ core of 4 is planar with no intermolecular interactions and nearly- $C_{2}$ symmetry (Figure $1 \mathrm{~d}$ ). The $\mathrm{Bi}-\mathrm{N}$ bond lengths fall between covalent and dative $\mathrm{Bi}-\mathrm{N}$ bonds. Most importantly, the $\mathrm{C}-\mathrm{N}$ distances in 4 are significantly shorter [average 1.374(5) Å] than those found in 2, $\mathbf{3}_{\mathrm{dim}}$, and $\mathbf{3}(\mathrm{dma})_{2}$, indicating imine character, which can be explained by invoking partial ligand oxidation from a triamido form to an amido bis-imine form that stabilizes a $\mathrm{Bi}^{l}$ centre (see Chart $1, \mathrm{H}$ ). The ${ }^{13} \mathrm{C}$ CP/MAS spectrum of this compound is expectedly very simple due to the two-fold symmetry and a single independent molecule in the unit cell (Figure S4).

In summary, compounds $\mathbf{1 , 2}$, and $\mathbf{4}$ are monomeric while $\mathbf{3}$ is dimeric in the solid state $\left(\boldsymbol{3}_{\mathrm{dim}}\right)$ by virtue of covalent $\mathrm{N}-\mathrm{Sb}$ bonds between the two halves. Compounds 1 and $\mathbf{2}$ adopt bent configurations around the central pnictogen, whereas 4 is planar. Compound $\mathbf{3}(\mathbf{d m a})_{2}$ provides a model for the monomeric structure of $\mathbf{3}$ in the solid state, revealing a planar $\mathrm{SbN}_{3}$ arrangement that is analogous to the $\mathrm{BiN}_{3}$ geometry in $\mathbf{4}$. We infer that the distinction between a bent geometry (as found in $\mathbf{3}_{\mathrm{dim}}$ ) and planar geometry around $\mathrm{Sb}$ is energetically minimal and this is borne out by solution spectroscopy experiments described below.

\subsection{Solution-Phase Structures}

\subsubsection{NMR Spectroscopy}

The ${ }^{1} \mathrm{H}$ NMR spectra of $1-4$ at $298 \mathrm{~K}_{\text {in }} \mathrm{C}_{6} \mathrm{D}_{6}$ exhibit four resonance in the aromatic region and a single resonance for the $\mathrm{Si}\left(\mathrm{CH}_{3}\right)_{3}$ group. While these features are expected for 4 based on its $C_{2}$-symmetric solid-phase structure, the detection of a single set of resonances is inconsistent with the structure assigned to 1, 2 and $3_{\text {dim }}$ through X-ray crystallography and CP/MAS NMR spectroscopy. This inconsistency is easily reconciled for $\mathbf{1}$ and $\mathbf{2}$ by invoking conformational flexibility in the solution phase at ambient temperature. For compound $\boldsymbol{3}_{\text {dim }}$, the detection of only four aromatic resonances in solution requires 
either i) conversion of formally covalent bonds to dative bonds followed by dissociation to give a symmetric monomeric form (i.e. 3), or ii) a rapid side-to-side motion of the subunits that renders them equivalent on the NMR timescale without loss of the overall dimeric formulation. To distinguish between these possibilities and to assess the scope of such dimerization more broadly, variable temperature NMR spectroscopy was used to understand the solution-phase dynamics in 1-4.

Figure 2. Top: Mole fractions of $\mathbf{3}, \boldsymbol{3}_{\mathrm{dim}}$, and $\boldsymbol{3}_{\mathrm{dim}}$ in a toludene- $\mathrm{d}_{8}$ solution as a function of temperature. Bottom: van't Hoff plot constructed with the mole fraction data.
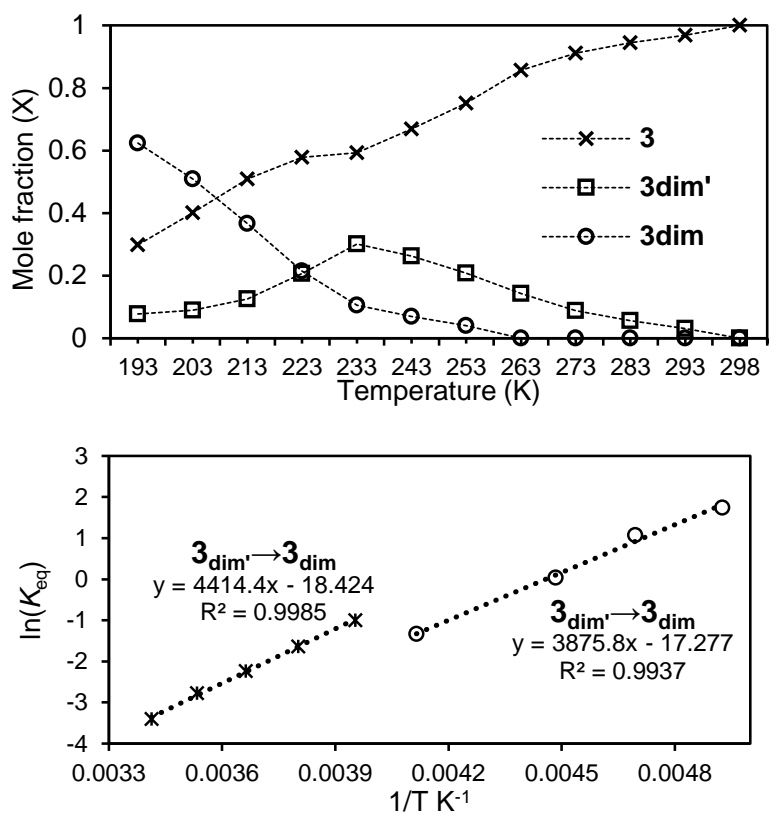

Compounds 1, 2, and 4 showed no change in their ${ }^{1} \mathrm{H}$ NMR spectrum upon cooling to $193 \mathrm{~K}$ in toluene$\mathrm{d}_{8}$. In contrast, the ${ }^{1} \mathrm{H}$ NMR spectrum of redissolved crystals of $\boldsymbol{3}_{\text {dim }}$ showed three species upon cooling with the composition of the sample varying with temperature (Figure 2, top). Given that we observe distinct speciation rather than signal decoalescence as a function of temperature, we rule out a dynamic side-to-side motion of subunits as the origin of the highly symmetric resonances observed at ambient temperature.

Figure 3. Proposed equilibria between $\mathbf{3}, \mathbf{3}_{\mathrm{dim}}$ and $\mathbf{3}_{\mathrm{dim}}$.

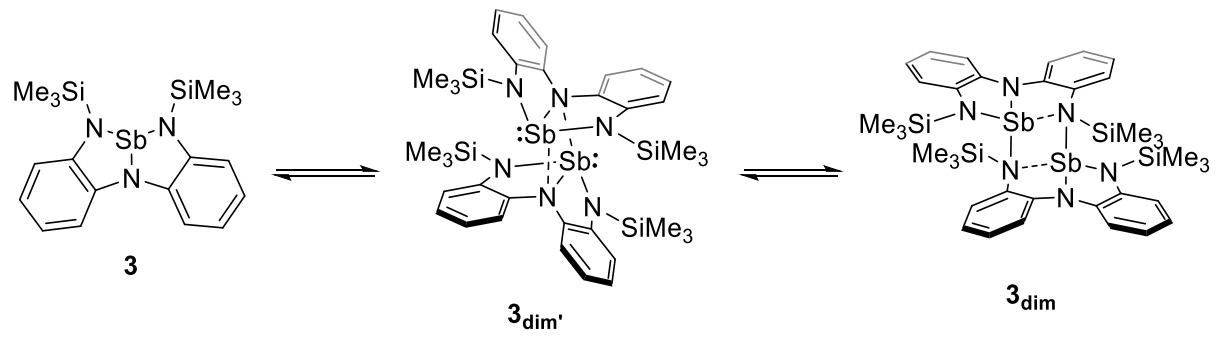

One of the three sets of signals observed at $193 \mathrm{~K}$ matches the spectrum obtained at $298 \mathrm{~K}$, which exhibits four aromatic resonances and a single resonance for the $\mathrm{Si}\left(\mathrm{CH}_{3}\right)_{3}$ groups and we assign it to monomeric $\mathbf{3}$ as modelled by $\mathbf{3}(\mathbf{d m a})_{2}$. The second species exhibits eight resonances for the aromatic 
region and two for the $\mathrm{Si}\left(\mathrm{CH}_{3}\right)_{3}$ groups and is assigned to the crystallographically observed $3_{\text {dim. }}$. DFTcalculated NMR chemical shifts for $\mathbf{3}_{\text {dim }}$ are in excellent agreement with experimentally observed values (Figure S6). Moreover a NOESY experiment at $208 \mathrm{~K}$ confirmed the spatial proximity of one set of $\mathrm{Si}\left(\mathrm{CH}_{3}\right)_{3}$ protons in $\mathbf{3}_{\mathrm{dim}}$ to the aromatic protons ortho to the central nitrogen atom (Figure S7). The other set of $\mathrm{Si}\left(\mathrm{CH}_{3}\right)_{3}$ protons only shows proximity to the aromatic protons ortho to the external nitrogen atoms. For comparison, the $\mathrm{Si}\left(\mathrm{CH}_{3}\right)_{3}$ signal assigned to monomeric 3 do not show proximity to the protons ortho to the central nitrogen atoms. The third species (denoted as $\mathbf{3}_{\text {dimm}^{\prime}}$ ) behaves as an intermediate and exhibits eight aromatic resonances and two $\mathrm{Si}\left(\mathrm{CH}_{3}\right)_{3}$ groups. We tentatively identify it as a dimer formed via the central rather than external nitrogen atoms (i.e. dative Sb1-N1-Sb1'-N1' interactions) with the mirror symmetry lost due to tilt to accommodate a stereochemically active lone pair at $\mathrm{Sb}$. Such a species is indeed found to be a weakly bound but stable entity as per DFT calculations and can be viewed as two bent molecules of 3 interacting via dative N-Sb interactions (Figure S8). Thus, one monomeric species, $\mathbf{3}$, and two dimeric species, $\mathbf{3}_{\mathrm{dim}}$, and $\mathbf{3}_{\mathrm{dim}}$, exist in equilibrium. Monomeric $\mathbf{3}$ is the dominant species at $298 \mathrm{~K}$ and upon cooling it dimerizes to the weakly-bound $\boldsymbol{3}_{\text {dim' }}$, which subsequently rearranges to $\boldsymbol{3}_{\text {dim }}$ at the lowest temperatures studied (Figure 3).

Table 2. Experimental thermodynamic parameters $\left(\mathrm{kcal} \mathrm{mol}^{-1}\right)$ determined for the dimerization of 3 via variable temperature NMR spectroscopy.

$\begin{array}{llll} & \mathbf{3} \rightarrow \mathbf{3}_{\mathrm{dim}}, & \mathbf{3}_{\mathrm{dim}} \rightarrow \mathbf{3}_{\mathrm{dim}} & \mathbf{3 \rightarrow \mathbf { 3 } _ { \mathrm { dim } }} \\ \boldsymbol{\Delta} \boldsymbol{H} & -8.77 \pm 0.20 & -7.70 \pm 0.44 & -16.47 \pm 0.64 \\ \boldsymbol{\Delta} \boldsymbol{S} & -0.037 \pm 0.001 & -0.034 \pm 0.002 & -0.071 \pm 0.003 \\ \boldsymbol{\Delta} \boldsymbol{G}_{193 \mathrm{~K}} & -1.71 \pm 0.29 & -1.08 \pm 0.73 & -2.79 \pm 1.02 \\ \boldsymbol{\Delta} \boldsymbol{G}_{298 \mathrm{~K}} & +2.13 \pm 0.29 & +2.53 \pm 0.73 & +4.66 \pm 1.02\end{array}$

A van't Hoff plot (Figure 2, bottom) yielded thermodynamic parameters (Table 2) that are aligned with the proposed sequence of events. While dimerization of $\mathbf{3}$ to give $\mathbf{3}_{\mathrm{dim}}$, shows the expected large negative entropy change, we were surprised that rearrangement of $\boldsymbol{3}_{\mathrm{dim}}$, to $\boldsymbol{3}_{\mathrm{dim}}$ is also accompanied by a significant decrease in entropy. We attribute this to the drastic change in the strength and lengths of the bonds between the subunits in the two dimers. Specifically, $\boldsymbol{3}_{\text {dim' }}$ is calculated to have long dative interactions assembling the two subunits, whereas $\boldsymbol{3}_{\mathrm{dim}}$ is held together by short covalent bonds and is better described as a dinuclear macrocycle with intramolecular dative interactions. Greater conformational flexibility is anticipated in the weakly-bound $\boldsymbol{3}_{\mathrm{dim}}$, than in $\boldsymbol{3}_{\mathrm{dim}}$ and this factor is presumably responsible for the unusually large $\Delta S$ value for a dimer-to-dimer transformation. The reversible formation of covalent $\mathrm{N}-\mathrm{Sb}$ 
bonds studied in these experiments provides rare quantitative thermodynamic data for dynamic covalent chemistry involving antimony centres. ${ }^{33}$

\subsubsection{UV-VIS Spectroscopy}

Further insight into the solution phase structures was obtained by comparison of the experimental and TD-DFT calculated UV-Vis spectra of compounds 1-4. The experimental spectra for 1 and 2 feature no bands in the visible range, consistent with predictions from TD-DFT calculations for these compounds in their monomeric bent ground-states (Figure 4 a and b). In contrast, calculations employing planar models predict that prominent absorbances should be evident in the visible range for all compounds. Together with the NMR spectroscopy data, we infer that 1 and $\mathbf{2}$ exist predominantly as bent monomeric molecules in their ground state in solution, although due to the well-established facility of edge-inversion in such species a low-lying planar transition state is also expected (vide infra). ${ }^{34-38}$

Figure 4. Experimental (left) and calculated (right) UV-Vis spectra of 1-4 in pentane at $298 \mathrm{~K}$.

a)

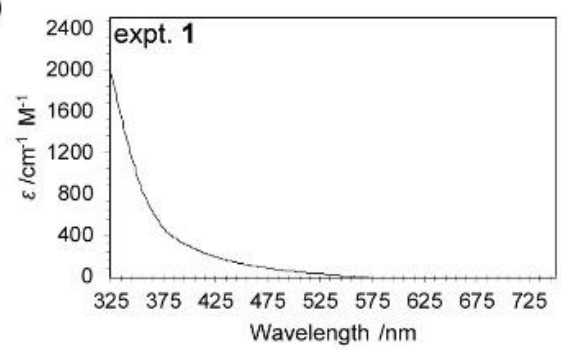

b)

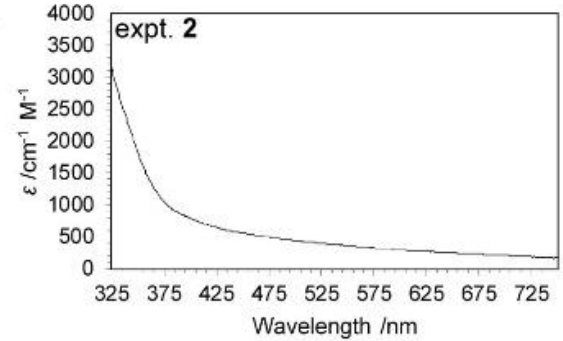

c)

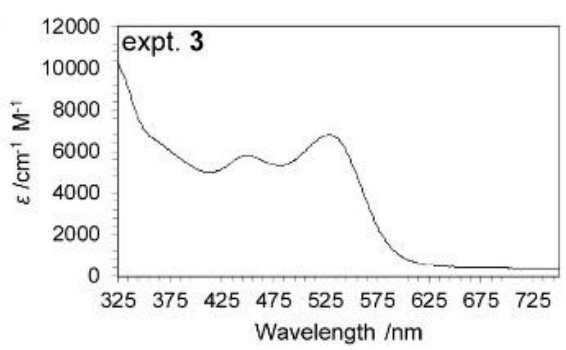

d)

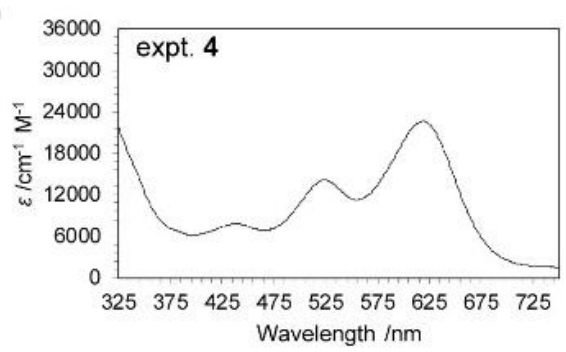

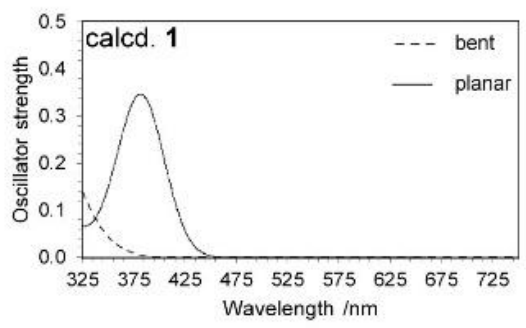
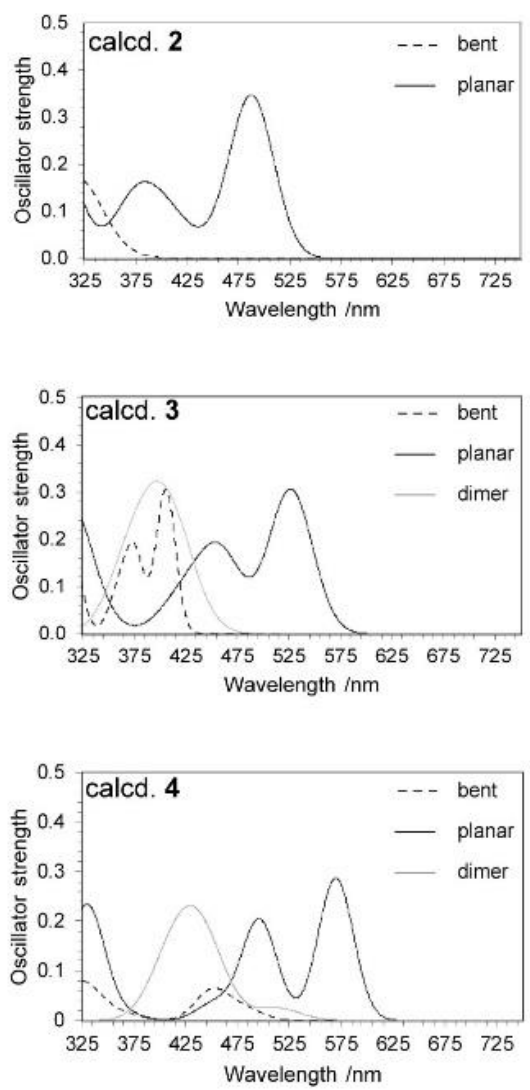
At $298 \mathrm{~K}$, the spectra of $\mathbf{3}$ and $\mathbf{4}$ in pentane exhibit two absorptions in the visible range, with values for the antimony analogue being hypsochromically shifted (Figure 4c and d). These number of spectral features and their relative positions agree with TD-DFT predictions based on the monomeric planar forms, but differ significantly from calculations performed on either the monomeric bent models or dimers $\mathbf{3}_{\text {dim }}$ and hypothetical $\mathbf{4}_{\mathrm{dim}}$. Upon cooling a solution of $\mathbf{3}$ in pentane to $193 \mathrm{~K}$, the prominent bands observed at $298 \mathrm{~K}(525 \mathrm{~nm}$ and $443 \mathrm{~nm}$ ) diminish substantially while the bands at ca. $385 \mathrm{~nm}$ decrease only marginally (Figure S9). Comparison of the experimental data with DFT-calculated spectra converges with the inference from NMR spectroscopy that upon cooling a solution of $\mathbf{3}$ appreciable amounts of $\boldsymbol{3}_{\text {dim' }}$ (calculated $\lambda_{\max }=407 \mathrm{~nm}$ from TD-DFT) and $\mathbf{3}_{\mathrm{dim}}$ (calculated $\lambda_{\max }=395 \mathrm{~nm}$ from TD-DFT) are formed resulting in the persistence of the bands around $390 \mathrm{~nm}$ even as bands from 3 decrease. Substantial overlap between absorbance maxima for the three species precluded a quantitative determination of thermodynamic parameters to compare with data obtained from NMR spectroscopy.

In summary, passage through a planar transition state notwithstanding, $\mathbf{1}$ and $\mathbf{2}$ exist primarily in their bent monomeric configuration in solution (pentane or toluene), whereas $\mathbf{3}$ and $\mathbf{4}$ exist as planar monomers. While 1, 2, and $\mathbf{4}$ show no temperature dependent dynamics, $\mathbf{3}$ dimerizes first to $\mathbf{3}_{\text {dim }}$ and then to $\boldsymbol{3}_{\text {dim }}$ upon cooling to $193 \mathrm{~K}$ (or upon crystallization). This remarkable diversity prompted a thorough investigation of the underlying electronic causes through DFT calculations as outlined in the following section.

\subsection{Gas-phase structures}

2.4.1 Structure and Bonding in Monomeric 1-4. We first consider the monomeric forms of $1-4$, for which the optimized ground state geometries are shown in Figure 5. Comparison of the calculated bond lengths and angles with the available structural data show good agreement with experimental lengths being within $0.05 \AA$. The calculations reproduce the asymmetric nature of the $E-N 2 / N 3$ ( $E=P, A s)$ interactions as observed in the crystal structure of 2 . They also confirm that a bent rather than planar geometry is most stable for $\mathbf{1}$ and $\mathbf{2}$. The optimized structures of monomeric $\mathbf{3}$ and $\mathbf{4}$ are planar with $C_{2}$ symmetry as inferred from the UV-Vis spectra and confirmed crystallographically for 4 . Moreover, comparing analogous metric parameters in monomeric $\mathbf{3}$ with the structure of $\mathbf{3}(\mathbf{d m a})_{2}$ showed very little deviation [maximum $0.04 \AA$ deviation within the $\mathrm{Sb}(\mathrm{N})_{3}$ core], suggesting that despite coordination of two ligands, $\mathbf{3}(\mathbf{d m a})_{2}$ provides an accurate model for the otherwise unisolable monomeric, planar $\mathbf{3}$. 
Figure 5. Calculated minima and selected metric parameters for the optimized structures of 1-4 at the PBE1-D3/def2-TZVPD level. Hydrogen atoms have been omitted for clarity.
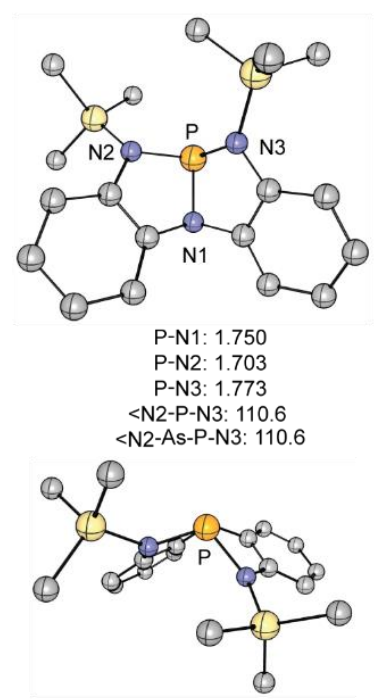

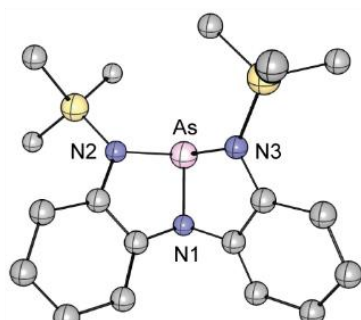

As-N1: 1.870

As-N2: 1.851

As-N3: 1.914

$<$ N2-As-N3: 110.0
$<$ N2-As-N1-N3: 110.2

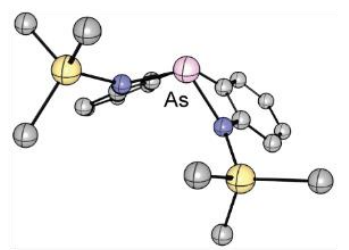

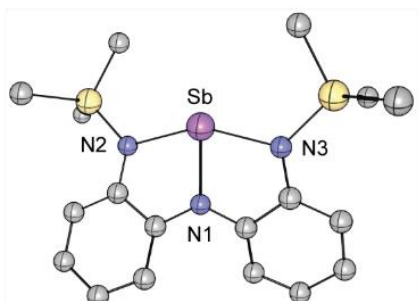

Sb-N1: 2.069

Sb-N2: 2.162

Sb-N3: 2.162

$<$ N2-Sb-N3: 152.4

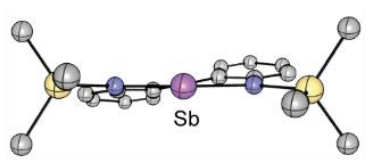

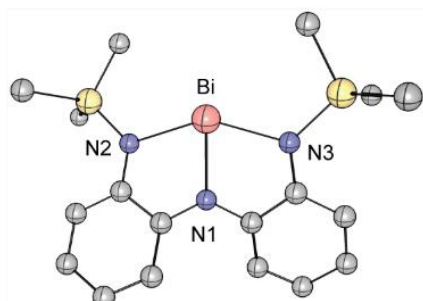

Bi-N1: 2.173

Bi-N2: 2.274

Bi-N3: 2.274

$<$ N2-Bi-N3: 147.2
$<$ N2-Bi-N1-N3: 180.0

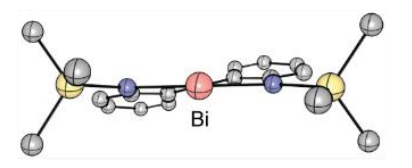

Plots of the electron density gradients within the two distinct $\mathrm{E}(\mathrm{N})_{2}(\mathrm{C})_{2}$ rings for each compound (Figure S10) are suggestive of a bonding situation where one of the rings expresses $\mathrm{N}$-heterocyclic pnictenium cation like features - high planarity and high ellipticity $(\varepsilon)$ at the E-N3 bond critical point (bcp) - while the other ring contains an anionic amido substituent and exhibits reduced planarity and low $\varepsilon$ at the E-N2 bcp. For example, the ellipticity at the $\mathrm{P}-\mathrm{N} 3 \mathrm{bcp}$ is 0.21 and comparable to the value for the P-N1 bcp (0.19), but $\varepsilon$ for the $\mathrm{P}-\mathrm{N} 2$ bcp is only 0.06 . The ring comprised of $\mathrm{P}-\mathrm{N} 1-\mathrm{C}-\mathrm{C}-\mathrm{N} 2$ atoms is consistently substantially planar compared to the ring comprised of the $\mathrm{P}-\mathrm{N} 1-\mathrm{C}-\mathrm{C}-\mathrm{N} 3$ atoms. This partial phosphenium-like character results in high $\mathrm{P}-\mathrm{N}$ bond polarity, and is fully consistent with the reported facility of $\mathrm{P}-\mathrm{N}$ bond heterolysis in analogues of $1 .^{12}$

The NBO and QTAIM results for 3 and 4 reflect their symmetric $C_{2}$ structures and the more ionic E-N bonding in these compounds, which leads to lower values for the WBls and $\rho$ for $E-N$ bonds $(E=S b, B i)$. The ellipticity at the E-N2 and E-N3 bcps are on average higher than those found in 1 and 2 (0.19 for E $=\mathrm{Sb}, 0.18$ for $\mathrm{E}=\mathrm{Bi})$ and the $\varepsilon$ at the $\mathrm{E}-\mathrm{N} 1 \mathrm{bcps}$ are the highest amongst all calculated values $(0.25$ for $\mathrm{E}=\mathrm{Sb}, 0.23$ for $\mathrm{E}=\mathrm{Bi}$ ). These data indicate greater $\pi$-delocalization over the planar heteroatom framework in $\mathbf{3}$ and $\mathbf{4}$ than in $\mathbf{1}$ and $\mathbf{2}$. The NBOs of $\boldsymbol{3}_{\mathrm{dim}}$ (see Figure S11) support the presence of three covalent $\mathrm{N}-\mathrm{Sb}$ bonds in a bent arrangement and one dative $\mathrm{N}-\mathrm{Sb}$ bond with the WBI for the latter $(0.16)$ being significantly smaller than the values for the former (0.44-0.54).

The influence of ligand strain due to the size of the central element was deconvoluted from intrinsic electronic effects by comparing the single point energies of the triamido substituents frozen in both the bent and planar geometries of monomeric 1-4 (Figure S14). The calculations were conducted with a 3charge on the substituent (implying N-E bond heterolysis) as well as a quartet neutral ground state (implying N-E bond homolysis). Considering N-E heterolysis, the planar ligand geometry was found to be 
significantly more stable for all derivatives with the preference for planarity increasing in the order $\mathrm{Bi}<$ $\mathrm{Sb}<\mathrm{P} \approx \mathrm{As}$, which is contrary to the experimental trend. When N-E homolysis is assumed, the bent geometries are uniformly found to be more favoured, which is also inconsistent with the experimental findings. Thus, ligand deformation energies alone cannot be used to rationalize the observed periodic trends.

Table 3. Calculated NBO and QTAIM parameters for 1-4 and $\mathbf{3}_{\mathrm{dim}}$. The quantities $\rho\left(\mathrm{r}_{\mathrm{bcp}}\right)$ and $\varepsilon\left(\mathrm{r}_{\mathrm{bcp}}\right)$ denote electron density and bond ellipticity, respectively, at the bond critical point between a given E-N pair.

\begin{tabular}{|c|c|c|c|c|}
\hline Compound & $\mathbf{N}$ & WBI (E-N) & $\rho\left(r_{b c p}\right)$ & $\varepsilon\left(r_{b c p}\right)$ \\
\hline 1 & $\mathrm{~N} 1$ & 0.78 & 0.16 & 0.19 \\
\hline \multirow[t]{2}{*}{$E=P$} & $\mathrm{~N} 2$ & 0.85 & 0.15 & 0.06 \\
\hline & N3 & 0.71 & 0.16 & 0.21 \\
\hline 2 & $\mathrm{~N} 1$ & 0.74 & 0.15 & 0.21 \\
\hline \multirow[t]{2}{*}{$E=A s$} & N2 & 0.77 & 0.13 & 0.14 \\
\hline & N3 & 0.66 & 0.15 & 0.29 \\
\hline 3 & $\mathrm{~N} 1$ & 0.71 & 0.11 & 0.25 \\
\hline \multirow[t]{2}{*}{$E=S b$} & $\mathrm{~N} 2$ & 0.57 & 0.09 & 0.19 \\
\hline & N3 & 0.57 & 0.09 & 0.19 \\
\hline $3_{\text {dim }}$ & N1 & 0.54 & 0.12 & 0.16 \\
\hline \multirow[t]{3}{*}{$E=S b$} & $\mathrm{~N} 2$ & 0.54 & 0.11 & 0.12 \\
\hline & N3 & 0.16 & 0.04 & 0.12 \\
\hline & N3' & 0.44 & 0.10 & 0.07 \\
\hline 4 & N1 & 0.69 & 0.10 & 0.24 \\
\hline \multirow[t]{2}{*}{$\mathrm{E}=\mathrm{Bi}$} & $\mathrm{N} 2$ & 0.53 & 0.08 & 0.18 \\
\hline & N3 & 0.53 & 0.08 & 0.18 \\
\hline
\end{tabular}

We therefore turned to the Morokuma energy decomposition analysis (EDA) scheme to investigate this system. The $\Delta \Delta E$ values in Table 4 represent the instantaneous energy changes - dissected into the Pauli, orbital, electrostatic, dispersion, and solvation contributions - that accompany a mutation from the bent to the planar geometry for compounds 1-4. The results qualitatively capture the increased facility of planarization upon descending the group, with orbital interactions serving as the primary driving factor in achieving the planar geometries (see $\Delta \Delta E_{\text {orb }}$ values). Considering the extent of stabilization, the values 
can be grouped into the lighter (P: $-63.5 \mathrm{kcal} \mathrm{mol}^{-1}$, As: $-59.5 \mathrm{kcal} \mathrm{mol}^{-1}$ ) and heavier (Sb: $-81.1 \mathrm{kcal} \mathrm{mol}^{-}$ 1, Bi: $-88.5 \mathrm{kcal} \mathrm{mol}^{-1}$ ) elements. Enhanced orbital stabilization of the 3-centre-4-electron bond, as imposed by the planar geometry but not the bent geometry, has previously been theoretically predicted when the electronegativity difference between the bonding partners increases. ${ }^{37}$ Moreover, the electrostatic interactions penalty for adopting the planar geometry is also less for the heavier pnictogens (Sb: $26.3 \mathrm{kcal} \mathrm{mol}^{-1}$; $\mathrm{Bi}: 24.3 \mathrm{kcal} \mathrm{mol}^{-1}$ ) than for the lighter ones (P: $39.0 \mathrm{kcal} \mathrm{mol}^{-1}$; As: $37.0 \mathrm{kcal} \mathrm{mol}^{-1}$ ). As anticipated from the minimal change in hydrodynamic radii, solvation and dispersion effects have a very small influence upon the geometry outcomes. The combination of these effects leads to the experimentally observed trend that the preference for adopting a planar geometry increases in the order $\mathrm{P}<\mathrm{As}<$ $\mathrm{Sb}<\mathrm{Bi}$.

Table 4. Energy decomposition analysis for transforming the bent conformations of 1-4 into the planar conformations. All energies are in $\mathrm{kcal} / \mathrm{mol}$.

$\begin{array}{lllll} & \mathbf{1} & \mathbf{2} & \mathbf{3} & \mathbf{4} \\ \Delta \Delta E_{\text {int }} & 6.1 & -1.6 & -5.4 & -9.6 \\ \Delta \Delta E_{\text {Pauli }} & 28.1 & 18.1 & 45.9 & 50.4 \\ \Delta \Delta E_{\text {elstat }} & 39.0 & 37.0 & 26.3 & 24.3 \\ \Delta \Delta E_{\text {orb }} & -63.5 & -59.5 & -81.1 & -88.5 \\ \Delta \Delta E_{\text {disp }} & 1.7 & 1.8 & 1.9 & 1.8 \\ \Delta \Delta E_{\text {solv }} & 0.9 & 1.1 & 1.6 & 2.4 \\ \Delta \Delta G_{298 K} & 15.1 & 6.5 & 0.8 & -2.4\end{array}$

The above trend is also observed when thermally corrected Gibbs energies (at $298 \mathrm{~K}$ ) rather than electronic energies (at $0 \mathrm{~K}$ ) are considered (see $\Delta \Delta G_{298 \mathrm{~K}}$ values in Table 4). Since the planar structures model the transition states for edge-inversion in 1,2 , and 3, the $\Delta \Delta G_{298 \mathrm{~K}}$ values also reveal the periodic trend in edge inversion barriers for trivalent pnictogens, with bismuth derivative $\mathbf{4}$ being exceptional due to its planar structure being the ground rather than the transition state. The decrease in barrier height for this inversion descending the group has been theoretically predicted before for the series $\mathrm{EF}_{3}(\mathrm{E}=\mathrm{N}$ Bi). ${ }^{34,37,39}$

\subsubsection{Structure and Bonding in Dimers of 3 and 4}


Given that $\mathbf{3}$ and $\mathbf{4}$ exhibit similar solution-phase and calculated minimum structures (planar and monomeric), we sought to answer the following question: why does $\mathbf{3}$ dimerize to give $\mathbf{3}_{\mathrm{dim}}$ in the solid-state while 4 does not?

The gas-phase structures of $\boldsymbol{3}_{\mathrm{dim}}$ and the hypothetical $\mathbf{4}_{\mathrm{dim}}$ were optimized (Figure 8 ). The calculated structure of $3_{\text {dim }}$ duplicates the substantial difference between the Sb-N2 bond length [calc. 2.072 $\AA$, expt. 2.074(4) $\AA$ ] and the Sb-N3 bond length [calc. 2.614 A, expt. 2.633(4) Å] observed crystallographically, and is therefore consistent with the interpretation from the solid-state data that $\mathrm{Sb}-\mathrm{N} 1, \mathrm{Sb}-\mathrm{N} 2$, and $\mathrm{Sb}-$ N3' define the covalent Sb-N bonds, while the Sb-N3 interaction is dative.

Figure 8. Optimized structures and selected structural parameters for $\mathbf{3}_{\text {dim }}$ and $\mathbf{4}_{\text {dim. }}$. Values in square brackets denote experimental data, where available. Bond lengths are given in $\AA$ and bond angles in degrees.
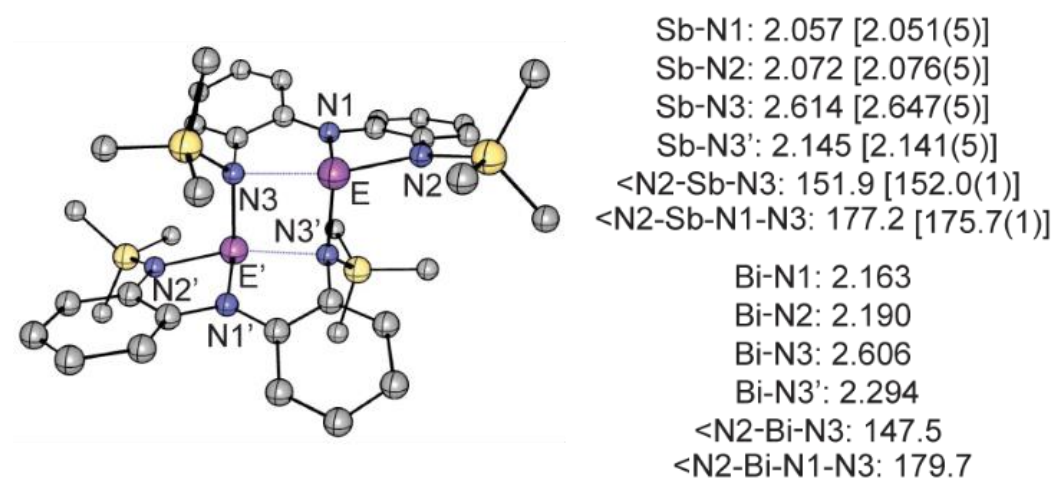

The EDA results for the $\mathbf{3} \rightarrow \mathbf{3}_{\text {dim }}$ and $\mathbf{4} \rightarrow \mathbf{4}_{\text {dim }}$ dimerizations (Table 5 ) show that dispersive forces play a large role (ca. $22 \mathrm{kcal} \mathrm{mol}^{-1}$ ) in both cases. The process is more favourable for the antimony analogue $\left(\Delta \mathrm{E}_{\text {int }}=-60.2 \mathrm{kcal} \mathrm{mol}^{-1}\right)$ than the bismuth case $\left(\Delta E_{\text {int }}=-47.9 \mathrm{kcal} \mathrm{mol}^{-1}\right)$. Although the purely electronic interaction energies for dimerization are both large and negative, inclusion of thermal and entropy effects reduces them to $\Delta G$ values of $-7.4 \mathrm{kcal} \mathrm{mol}^{-1}$ for $\boldsymbol{3}_{\mathrm{dim}}$ and $-5.9 \mathrm{kcal} \mathrm{mol}^{-1}$ for $\mathbf{4}_{\mathrm{dim}}$. Considering the size of the system (100 atoms in each dimer) and the error anticipated in DFT calculations for such cases (5-10 $\mathrm{kcal} \mathrm{mol}^{-1}$ ), the calculated small magnitudes are consistent with the experimental data in Table 2.

Inspection of the individual energetic components reveals that the major stability differences between the two dimers arise from the destabilizing Pauli repulsion $\left(94.9 \mathrm{kcal} \mathrm{mol}^{-1}\right.$ greater in $\left.\boldsymbol{3}_{\mathrm{dim}}\right)$, the stabilizing electrostatic potential $\left(50.4 \mathrm{kcal} \mathrm{mol}^{-1}\right.$ greater in $\mathbf{3}_{\mathrm{dim}}$ ) and the stabilizing orbital interaction (ca. $56.6 \mathrm{kcal}$ $\mathrm{mol}^{-1}$ greater in $\mathbf{3}_{\mathrm{dim}}$ ) terms. For comparison, contributions from the solvation, geometric deformation, and dispersion terms are within $10 \mathrm{kcal} \mathrm{mol}^{-1}$ for the two derivatives. We propose that the $\mathrm{Bi}-\mathrm{N} 3$ ' bond length being $0.147 \AA$ longer than the Sb-N3' bond reduces Pauli repulsion in $\mathbf{4}_{\text {dim }}$ by better separating the ligands in this compound. This long bond length also diminishes the electrostatic stabilization in $\mathbf{4}_{\text {dim }}$ by enforcing a greater separation of the electropositive $\mathrm{Bi}$ and electronegative $\mathrm{N}$ atoms. The 
electronegativities of $\mathrm{Sb}\left(X_{\mathrm{Pauling}}=2.1\right)$ and $\mathrm{Bi}\left(X_{\mathrm{Pauling}}=2.0\right)$ are similar and unlikely to be the source of the large difference in electrostatic attraction. We further propose that the more diffuse $6 p$ valence orbitals of bismuth overlap poorly with their nitrogen $2 p$ bonding counterparts compared to the $\mathrm{Sb} 5 \mathrm{p}$ valence orbital, accounting for more favourable orbital interactions as indicated by EDA results for $\boldsymbol{3}_{\text {dim. }}$. Considering these factors together with the more pronounced preference towards planarity for monomeric $\mathbf{4}$ fully accounts for the experimental observations that $\mathbf{3}_{\mathrm{dim}}$ is accessible at $193 \mathrm{~K}$ in solution but $\mathbf{4}_{\mathrm{dim}}$ is not detected.

Table 5. Energy decomposition analysis for the formation of $\mathbf{3}_{\mathrm{dim}}$ from $\mathbf{3}$ and $\mathbf{4}_{\mathrm{dim}}$ from $\mathbf{4}$. All energies are in $\mathrm{kcal} / \mathrm{mol}$. Percentages denote fraction of attractive forces represented by each component. The value $r$ denotes the distance between the monomers and is given in $\AA$.

$\begin{array}{lll} & 3_{\text {dim }} & \mathbf{4}_{\text {dim }} \\ \Delta E_{\text {int }} & -60.2 & -47.9 \\ \Delta E_{\text {Pauli }} & 431.6 & 336.7 \\ \Delta E_{\text {elstat }} & -261.1(53.1 \%) & -210.7(54.7 \%) \\ \Delta E_{\text {orb }} & -206.3(41.9 \%) & -149.7(38.9 \%) \\ \Delta E_{\text {disp }} & -22.8(4.6 \%) & -22.1(5.8 \%) \\ \Delta E_{\text {solv }} & -1.6(0.3 \%) & -2.1(0.5 \%) \\ \Delta E_{\text {prep }} & 47.6 & 36.6 \\ r & 2.147 & 2.294 \\ D_{\mathrm{e}} & 12.6 & 11.3 \\ \Delta G_{298 \mathrm{~K}} & -7.4 & -5.9\end{array}$

\subsection{Implications for Reactivity}

To assess whether the structural trends described above modulate the reactivity of compounds 1-4, we analyzed their frontier orbital manifolds in both geometries (Figure S12). All three p-orbitals are engaged in E-N $\sigma$ bonding in the bent case. In contrast, the planar geometry only engages two of three p-orbitals by virtue of a 3-centre-4-electron bonds involving the external E-N bonds. Consequently, in the planar geometry, a vacant p-orbital remains available perpendicular to the molecular plane at the central element and it is the LUMO in each case. Ligand oxidation transfers two electrons into this LUMO (see resonance structures for $\mathbf{H}$ in Chart 1) and was found to be responsible for the $\mathrm{Bi}(\mathrm{I})$ like reactivity reported for $\mathbf{4} .^{20}$ 
The LUMO in the bent geometry is E-N $\sigma^{*}$ in nature and appears trans to the central E-N bond as expected for the +III oxidation state of pnictogen amides.

While the HOMO energies are essentially unaltered by geometric perturbation, the LUMO energies are significantly lowered (ca. $1 \mathrm{eV}$ ) upon planarization. The closing of the HOMO-LUMO gap is consistent with experimental UV-Vis spectra (Figure 4), where the calculated and observed HOMO $\rightarrow$ LUMO excitation bands are uniformly red-shifted upon descending the group.

As the exceptional reactivity of constrained geometry phosphorus complexes is believed to initiated via nucleophilic attack by substrate (e.g. amines, alcohols, water) upon phosphorus, , ${ }^{9}$ 14-15 we were particularly interested in implications of the above frontier orbital considerations on Lewis acidity at the central pnictogen. In this context, the calculated trends result in two predictions: i) derivatives that are predominantly bent in the solution phase and with high inversion barriers (1 and 2) should exhibit lower Lewis acidity compared to derivatives that are predominantly planar ( 3 and 4$)$, and ii) 4 (LUMO = $-2.52 \mathrm{eV}$ ) should be more Lewis acidic than $3($ LUMO = -2.35 eV). We therefore reacted 1-4 with pyridine $\mathrm{N}$-oxide as a minimally sterically hindered Lewis base (Scheme 2).

Figure 6. Calculated HOMO/LUMO energies for the bent and linear conformations of monomeric 1-4.

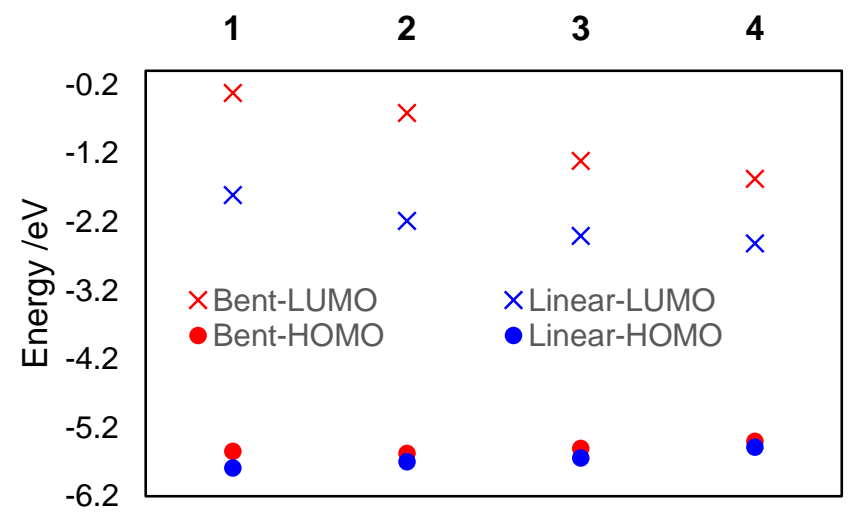

Scheme 2. Reactivity of 1-4 towards pyridine N-oxide

a)



$E=P, 1$

$E=A s, 2$

b)

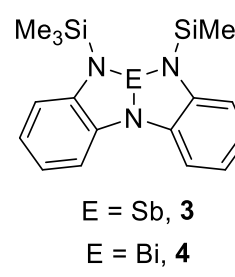

$+2$<smiles></smiles>

$\longrightarrow$ no reaction

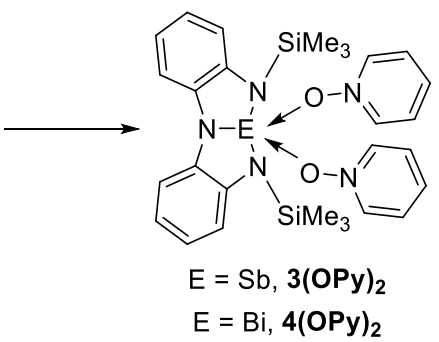


No reaction was observed between pyridine $\mathrm{N}$-oxide and either 1 or 2 . On the other hand, 2:1 adducts $\mathbf{3}(\text { pyo })_{2}$ and $\mathbf{4}(\text { pyo })_{2}$ were readily isolated from reaction involving 3 and $\mathbf{4}$, evidencing the increasing Lewis acidity of the predominantly planar compounds relative to the their bent analogues. Both compounds have been isolated and structurally characterized by crystallography (Figure 7). Next, the Gutmann-Beckett method was used to experimentally compare the Lewis acidity of $\mathbf{3}$ and $\mathbf{4}$. In the presence of excess Lewis acid, the ${ }^{31} \mathrm{P}$ chemical shift of triethylphosphine oxide is shifted to more downfield values in 4 relative to 3 (Figure S13). Conversion of the chemical shifts to acceptor numbers gives values of 15 and 28 for the antimony and bismuth derivatives, respectively, evidencing the higher Lewis acidity for the heavier analogue. Solvent-corrected DFT calculations of the fluoride ion affinity (FIA) and global electrophilicity index (GEI) $)^{40}$ also confirm that 4 (FIA: $33 \mathrm{kcal} \mathrm{mol}^{-1}, \mathrm{GEl}: 2.70 \mathrm{eV}$ ) is more acidic than 3 (FIA: $28 \mathrm{kcal} \mathrm{mol}^{-}$ 1, GEl: $2.50 \mathrm{eV})$.

Figure 7. Views of the solid-state molecular structure of $\mathbf{3}(\text { pyo })_{2}$ (left) and $\mathbf{4}(\text { (pyo) })_{2}$ (right). Non-essential hydrogen atoms have been omitted and the $\mathrm{CH}_{3}$ portions of the $\mathrm{Si}\left(\mathrm{CH}_{3}\right)_{3}$ groups have been truncated for clarity. Thermal ellipsoids are drawn at the $50 \%$ probability level.
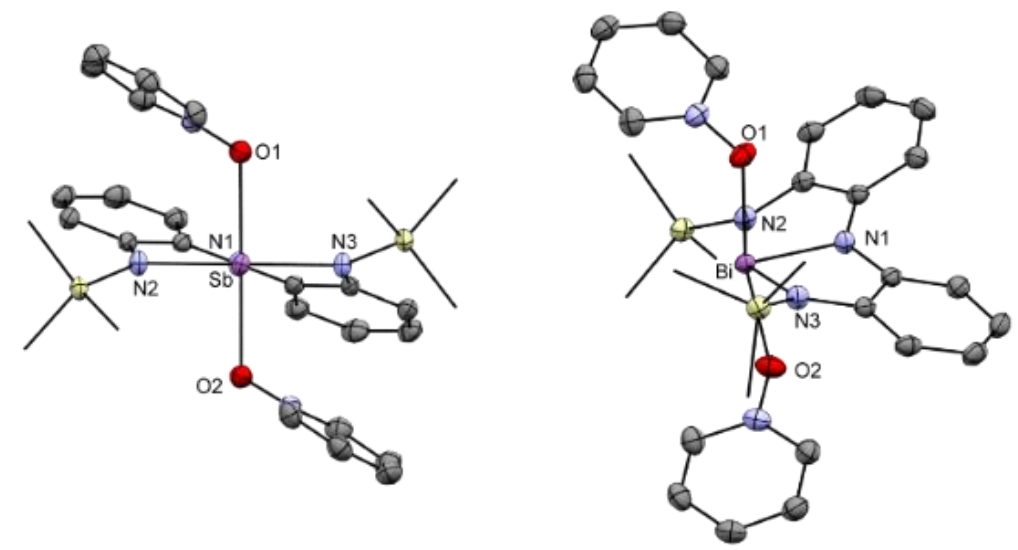

\subsection{Conclusions}

We have described a comprehensive investigation of structure and bonding spanning the solid, solution, and gas-phases for pnictogen triamides within the context of a single geometry-restraining substituent. The trends emerging from analysis of this periodic dataset are summarized below:

i) The tendency to adopt a planar geometry increases descending the group. For example, the preference for planarity in 1-4 in the solid phase increases in the order $\mathrm{P}, \mathrm{As}<\mathrm{Sb}<\mathrm{Bi}$ as determined from $\mathrm{X}$ ray crystallography and CP/MAS spectroscopy, with the structure of $\mathbf{3}(\mathbf{d m a})_{2}$ serving as a model for monomeric 3. In solution, the corresponding trend is $\mathrm{P}, \mathrm{As}<\mathrm{Sb}, \mathrm{Bi}$ based on NMR and UV-Vis spectroscopy.

ii) DFT calculations reveal that the two main factors contributing to these trends are the electronegative difference across the $\mathrm{E}-\mathrm{N}$ bond (which influences the electrostatic and orbital components of bonding) 
and the number of electrons (which influences the Pauli repulsion). Notably, ligand deformation strain alone is not predictive of the geometric outcomes.

iii) The $5^{\text {th }}$ row element antimony is identified as an inflection point between the behaviour of the lighter pnictogens and bismuth. It exhibits a structural promiscuity that is unique amongst the studied compounds as shown by the equilibria involving $\mathbf{3}, \boldsymbol{3}_{\mathrm{dim}}$, and $\boldsymbol{3}_{\mathrm{dim}}$. By carefully studying these equilibria, we determined rare quantitative thermodynamic data for dynamic covalent chemistry involving antimony compounds.

iv) Compound 4 stands out due to its planar ground state in the solid, solution and gas phase and exhibits no dimerization due to large Pauli repulsion between the subunits as well as poor orbital overlap due to the long $\mathrm{Bi}-\mathrm{N}$ bonds.

v) Structural preferences in this homologous series have consequences for reactivity. The Lewis acidity was experimentally found to increase in the order $1,2<3<4$, which is predicted by considerations of their ground state geometries and LUMO levels (the HOMO levels are unaltered by geometric deformation).

We anticipate that these trends may be more broadly applicable to other p-block groups and therefore provide guidance for rationally evolving the geometric deformation strategy in main group stoichiometric and catalytic chemistry.

Acknowledgments: We acknowledge the Natural Sciences and Engineering Resesarch Council (NSERC) of Canada, the Canada Foundation for Innovation (CFI), the Nova Scotia Research and Innovation Trust (NSRIT), and Dalhousie University for research funding. K.M.M. acknowledges the Vanier Canada Graduate Scholarships Program and the Walter C. Sumner Memorial Fellowships Program for funding. J. Z. acknowledges the Inorganic Chemistry Exchange (ICE) program. M.B.K. acknowledges the Sipekne'katic First Nation for a research stipend. S.J. acknowledges the Darrell and Emily Laing Foundation for a research award. D.N.L acknowledges the CFI and Research Nova Scotia Trust for supporting the X-ray diffraction facility.

Supporting Information: Experimental details, supporting figures, and spectra. Structural data has been deposited with the Cambridge Structural Database (1949722-1949726).

Corresponding Author: saurabh.chitnis@dal.ca 


\section{References:}

1. Gillespie, R. J., Fifty years of the VSEPR model. Coord. Chem. Rev. 2008, 252 (12), 1315-1327.

2. Chitnis, S. S.; LaFortune, J. H. W.; Cummings, H.; Liu, L. L.; Andrews, R.; Stephan, D. W., Phosphorus Coordination Chemistry in Catalysis: Air Stable P(III)-Dications as Lewis Acid Catalysts for the Allylation of C-F Bonds. Organometallics 2018, 37 (24), 4540-4544.

3. Chitnis, S. S.; Krischer, F.; Stephan, D. W., Catalytic Hydrodefluorination of C-F Bonds by an AirStable PIII Lewis Acid. Chem. Eur. J. 2018, 24 (25), 6543-6546.

4. Andrews, R. J.; Chitnis, S. S.; Stephan, D. W., Carbonyl and olefin hydrosilylation mediated by an air-stable phosphorus(iii) dication under mild conditions. Chem. Commun. 2019, 55 (39), 5599-5602.

5. Arduengo, A. J.; Stewart, C. A., Low coordinate hypervalent phosphorus. Chem. Rev. 1994, 94 (5), 1215-1237.

6. Culley, S. A.; Arduengo, A. J., Synthesis and structure of the first 10-P-3 species. J. Am. Chem. Soc. 1984, 106 (4), 1164-1165.

7. Stewart, C. A.; Harlow, R. L.; Arduengo, A. J., Chemistry and structure of the first 10-Sb-3 species. J. Am. Chem. Soc. 1985, 107 (19), 5543-5544.

8. Dunn, N. L.; Ha, M.; Radosevich, A. T., Main Group Redox Catalysis: Reversible PIII/PV Redox Cycling at a Phosphorus Platform. J. Am. Chem. Soc. 2012, 134 (28), 11330-11333.

9. Zhao, W.; McCarthy, S. M.; Lai, T. Y.; Yennawar, H. P.; Radosevich, A. T., Reversible Intermolecular E-H Oxidative Addition to a Geometrically Deformed and Structurally Dynamic Phosphorous Triamide. J. Am. Chem. Soc. 2014, 136 (50), 17634-17644.

10. Pistner, A. J.; Moon, H. W.; Silakov, A.; Yennawar, H. P.; Radosevich, A. T., Stable Open-Shell Phosphorane Based on a Redox-Active Amidodiphenoxide Scaffold. Inorg. Chem. 2017, 56 (15), 86618668.

11. Nykaza, T. V.; Harrison, T. S.; Ghosh, A.; Putnik, R. A.; Radosevich, A. T., A Biphilic Phosphetane Catalyzes N-N Bond-Forming Cadogan Heterocyclization via PIII/PV=0 Redox Cycling. J. Am. Chem. Soc. 2017, 139 (20), 6839-6842.

12. Lin, Y.-C.; Hatzakis, E.; McCarthy, S. M.; Reichl, K. D.; Lai, T.-Y.; Yennawar, H. P.; Radosevich, A. T., P-N Cooperative Borane Activation and Catalytic Hydroboration by a Distorted Phosphorous Triamide Platform. J. Am. Chem. Soc. 2017, 139 (16), 6008-6016.

13. Tanushi, A.; Radosevich, A. T., Insertion of a Nontrigonal Phosphorus Ligand into a Transition Metal-Hydride: Direct Access to a Metallohydrophosphorane. J. Am. Chem. Soc. 2018, 140 (26), 81148118.

14. Robinson, T. P.; De Rosa, D. M.; Aldridge, S.; Goicoechea, J. M., E-H Bond Activation of Ammonia and Water by a Geometrically Constrained Phosphorus(III) Compound. Angew. Chem. Int. Ed. 2015, 54 (46), 13758-13763.

15. Robinson, T. P.; De Rosa, D.; Aldridge, S.; Goicoechea, J. M., On the Redox Reactivity of a Geometrically Constrained Phosphorus(III) Compound. Chem. Eur. J. 2017, 23 (61), 15455-15465.

16. Volodarsky, S.; Dobrovetsky, R., Ambiphilic geometrically constrained phosphenium cation. Chem. Commun. 2018, 54 (50), 6931-6934.

17. Huang, K.; Dutton, J. L.; Martin, C. D., Exploiting Pincer Ligands to Perturb the Geometry at Boron. Chem. Eur. J. 2017, 23 (44), 10532-10535.

18. Kramer, N.; Jöst, C.; Mackenroth, A.; Greb, L., Synthesis of Electron-Rich, Planarized Silicon(IV) Species and a Theoretical Analysis of Dimerizing Aminosilanes. Chem. Eur. J. 2017, 23 (70), 17764-17774. 19. Ebner, F.; Greb, L., Calix[4]pyrrole Hydridosilicate: The Elusive Planar Tetracoordinate Silicon Imparts Striking Stability to Its Anionic Silicon Hydride. J. Am. Chem. Soc. 2018, 140 (50), 17409-17412. 20. Kindervater, M. B.; Marczenko, K. M.; Werner-Zwanziger, U.; Chitnis, S. S., A Redox-Confused Bismuth(I/III) Triamide with a T-Shaped Planar Ground State. Angew. Chem. Int. Ed. 2019, 58 (23), 78507855. 
21. Wang, F.; Planas, O.; Cornella, J., Bi(I)-Catalyzed Transfer-Hydrogenation with Ammonia-Borane. J. Am. Chem. Soc. 2019.

22. Šimon, P.; de Proft, F.; Jambor, R.; Růžička, A.; Dostál, L., Monomeric Organoantimony (I) and Organobismuth(I) Compounds Stabilized by an NCN Chelating Ligand: Syntheses and Structures. Angew. Chem. Int. Ed. 2010, 49 (32), 5468-5471.

23. Simon, P.; Jambor, R.; Ruzicka, A.; Dostal, L., Oxidative Addition of Diphenyldichalcogenides PhEEPh $(\mathrm{E}=\mathrm{S}$, Se, Te) to Low-Valent $\mathrm{CN}$ - and NCN-Chelated Organoantimony and Organobismuth Compounds. Organometallics 2013, 32 (1), 239-248.

24. Urbanova, I.; Jambor, R.; Ruzicka, A.; Jirasko, R.; Dostal, L., Synthesis and structure of N,Cchelated organoantimony(V) and organobismuth(V) compounds. Dalton Trans. 2014, 43 (2), 505-512.

25. Dostál, L., Quest for stable or masked pnictinidenes: Emerging and exciting class of group 15 compounds. Coord. Chem. Rev. 2017, 353, 142-158.

26. Raţ, C. I.; Silvestru, C.; Breunig, H. J., Hypervalent organoantimony and -bismuth compounds with pendant arm ligands. Coord. Chem. Rev. 2013, 257 (5), 818-879.

27. Kremláček, V.; Hyvl, J.; Yoshida, W. Y.; Růžička, A.; Rheingold, A. L.; Turek, J.; Hughes, R. P.; Dostál, L.; Cain, M. F., Heterocycles Derived from Generating Monovalent Pnictogens within NCN Pincers and Bidentate NC Chelates: Hypervalency versus Bell-Clappers versus Static Aromatics. Organometallics 2018, 37 (15), 2481-2490.

28. O'Reilly, M. E.; Veige, A. S., Trianionic pincer and pincer-type metal complexes and catalysts. Chem. Soc. Rev. 2014, 43 (17), 6325-6369.

29. Levason, W.; Maheshwari, S.; Ratnani, R.; Reid, G.; Webster, M.; Zhang, W., Structural Diversity in Supramolecular Complexes of $\mathrm{MCl} 3(\mathrm{M}=\mathrm{As}, \mathrm{Sb}, \mathrm{Bi})$ with Constrained Thio- and Seleno-Ether Ligands. Inorg. Chem. 2010, 49 (19), 9036-9048.

30. Levason, W.; Reid, G.; Zhang, W., The chemistry of the p-block elements with thioether, selenoether and telluroether ligands. Dalton Trans. 2011, 40 (34), 8491-8506.

31. Levason, W.; Light, M. E.; Maheshwari, S.; Reid, G.; Zhang, W., Unusual neutral ligand coordination to arsenic and antimony trifluoride. Dalton Trans. 2011, 40 (19), 5291-5297.

32. Chitnis, S. S.; Burford, N.; McDonald, R.; Ferguson, M. J., Prototypical Phosphine Complexes of Antimony(III). Inorg. Chem. 2014, 53 (10), 5359-5372.

33. Kořenková, M.; Hejda, M.; Erben, M.; Jirásko, R.; Jambor, R.; Růžička, A.; Rychagova, E.; Ketkov, S.; Dostál, L., Reversible C=C Bond Activation by an Intramolecularly Coordinated Antimony(I) Compound. Chem. Eur. J. 0 (ja).

34. Yamamoto, Y.; Chen, X.; Kojima, S.; Ohdoi, K.; Kitano, M.; Doi, Y.; Akiba, K.-y., Experimental Investigation on Edge Inversion at Trivalent Bismuth and Antimony: Great Acceleration by Intra- and Intermolecular Nucleophilic Coordination. J. Am. Chem. Soc. 1995, 117 (14), 3922-3932.

35. Akiba, K.-y.; Yamamoto, Y., Dynamic aspects of hypervalent compounds effected by the formation of three center-four electron bond in heteroatoms. Heteroat. Chem 2007, 18 (2), 161-175.

36. Dixon, D. A.; Arduengo, A. J.; Fukunaga, T., A new inversion process at Group VA (Group 15) elements. Edge inversion through a planar T-shaped structure. J. Am. Chem. Soc. 1986, 108 (9), 24612462.

37. Dixon, D. A.; Arduengo, A. J., Periodic trends in the edge and vertex inversion barriers for tricoordinate pnicogen hydrides and fluorides. J. Am. Chem. Soc. 1987, 109 (2), 338-341.

38. Dixon, D. A.; Arduengo III, A. J., Solvent stabilization of the edge inversion transition state in tetrahedral molecules. Int. J. Quantum Chem 1988, 34 (S22), 85-98.

39. Soran, A. P.; Silvestru, C.; Breunig, H. J.; Balazs, G.; Green, J. C., Organobismuth(III) dihalides with T-shaped geometry stabilized by intramolecular $\mathrm{N} \rightarrow \mathrm{Bi}$ interactions and related diorganobismuth(III) halides. ORGANOMETALLICS 2007, 26 (5), 1196-1203. 
40. Parr, R. G.; Szentpály, L. v.; Liu, S., Electrophilicity Index. J. Am. Chem. Soc. 1999, 121 (9), 19221924. 
TOC entry: We report a comprehensive analysis of periodic trends in structure, bonding, and reactivity for geometry constrained triamide complexes of $\mathrm{P}, \mathrm{As}, \mathrm{Sb}$, and $\mathrm{Bi}$. In this homologous series, the central element can adopt either a bent or planar geometry and the preferred orientation in the solid, solution, and gas phases have been mapped. The influence of geometry on reactivity has been elucidated and a rare dynamic self-assembly has been quantitatively established for antimony amides. These results provide guidance for further evolution of geometric deformation as a strategy for eliciting unusual reactivity in main group chemistry.

\section{TOC figure:}

$\mathrm{E}=\mathbf{P}, \mathbf{A s}, \mathbf{S b}, \mathbf{B i}$
structure and bonding:
(solid vs solution; bent vs planar)
dimerization (dynamic covalent
chemistry)
reactivity

